\title{
Effect of hyaluronic acid and vitamin E vaginal tablets on atrophic vaginitis: A randomized controlled trial
}

\author{
Sara Ziagham ${ }^{1}$, Zahra Abbaspoor $^{1 \star}$ and Mohammad Reza Abbaspour ${ }^{2}$ \\ ${ }^{1}$ Department of Midwifery, Faculty of Nursing and Midwifery, Ahvaz Jundishapur University of Medical Sciences, \\ Ahvaz, Iran. \\ ${ }^{2}$ Nanotechnology Research Center and School of Pharmacy, Ahvaz Jundishapur University of Medical Sciences, \\ Ahvaz, Iran.
}

Accepted 11 November, 2012

\begin{abstract}
The aim of this study was to compare the effectiveness of the vaginal tablet of hyaluronic acid and vitamin $E$ in the treatment of atrophic vaginitis. This randomized, double-blind comparison study was carried out on 40 postmenopausal women with symptoms of vaginal atrophy at number one health educational center of Ahvaz Jundishapur University of Medical Sciences, Ahvaz, Iran from August to December 2010. The women were randomized in two groups to take vaginal tablets containing $5 \mathrm{mg}$ hyaluronic acid sodium salt $(n=20)$ or $1 \mathrm{mg}$ vitamin $E(n=20)$ for 8 weeks. The symptoms of vaginal atrophy were evaluated by a self-assessed 4-point scale. Vaginal $\mathrm{pH}$ and maturation value were measured and compared in both groups. The results showed that the symptoms were relieved significantly in both the treatment groups $(p<0.001)$. The relief of symptoms was significantly superior in hyaluronic acid group (0.15) compared to vitamin $E$ group $(0.65)(p<0.05)$. A significant decrease in vaginal $\mathrm{pH}$ were detected in both treatment groups after treatment without difference between the two groups (HA group, $\mathrm{pH}=4.975$, vitamin $\mathrm{E}, \mathrm{pH}=5.125$ ). The vaginal maturation values were also significantly improved at both treatment groups $(p<0.001)$. The mean maturation value was significantly higher in hyaluronic acid group (60.52) compared to vitamin E group $(24.50)(p<0.001)$. Hyaluronic acid and vitamin E provided relief of vaginal symptoms, decreased vaginal $\mathrm{pH}$ and increased maturation of vaginal epithelium, but improvement was greater in hyaluronic acid group. Hence, hyaloronic acid vaginal tablet is suggested for women with vaginal atrophy who do not want to or cannot take local estrogen treatment.
\end{abstract}

Keywords: Menopause, vaginal atrophy, maturation value, hyaluronic acid, vitamin E.

\section{INTRODUCTION}

Urogenital atrophy is a common problem after menopause (Barlow et al., 1997). Follicular depletion of the ovary in menopause results in loss of estrogen, which is in turn the major cause of vulvo-vaginal dysfunction in older women. A lack of estrogen accounts for the anatomic, cytologic, physiologic, and bacteriologic genital changes that occur in women as they age (Mehta and Bachmann 2008). Symptoms of vaginal atrophy result

\footnotetext{
*Corresponding author. E-mail: Abbaspoorzahra7@Yahoo.com.
}

from a combination of atrophic changes in the estrogen dependent cells that line the vagina and a reduction in the secretion of cervical mucus which circulates in the vaginal lumen (vander Laak et al., 2002).

The clinical syndromes associated with vulvo-vaginal atrophy include vaginal dryness and irritation, dyspareunia, and recurrent urinary tract infections. Urogenital atrophy leads to decreases in the size of the uterus, ovaries, vaginal canal and vulva. Vaginal atrophy leads to the breakdown of collagen, smooth muscle and elastin in the vagina. Blood flow to the vagina is also reduced, leading to decreased transudation during sexual arousal 
as well as increased risk of trauma and pain (Johnston et al., 2004). The rise in the vaginal $\mathrm{pH}$, as well as thinning of the epithelium, increases the incidence of urinary tract yeast infections in women during perimenopause and after menopause (Weisberg et al., 2005). The vaginal pH in premenopausal women is less than 4.5 , which reflects the production of lactic acid by lactobacillus organisms. The vaginal $\mathrm{pH}$ increases to over 6 in postmenopausal women, due to a reduction in the colonization of the vagina by lactobacillus, secondary to a decrease in superficial cells and hence decreased glycogen, and the vaginal epithelium is thinner (Sturdee and Panay, 2010). These symptoms and disorders are common, progressive, and unlikely to resolve without treatment. However, only 20 to $25 \%$ of women who experience these symptoms will ultimately seek treatment for them (Pandit and Ouslander, 1997). The management options for atrophic vaginitis range from non-hormonal home remedies to several forms of local or systemic estrogen therapy.

Water-based lubricants, vaginal moisturizers, vitamin $D$, vitamin $E$ oil are some of the non-hormonal treatment options (Castelo-Branco et al., 2005). Vitamin E, a fatsoluble vitamin with great antioxidant properties, takes part in the metabolism of all cells. It prevents the degradation of the tissue due to oxidant agents. However, vitamin E, despite the lack of literature, has a ration in this context; it can be used on the skin, because of its antioxidant properties, anti-inflammatory and healing activity (Neggers et al., 2007).

Hyaluronic acid sodium salt is a high molecular weight substance which belongs to the group of glycosaminoglycans and consists of repetitive disaccharide units (glucoronic acid and $\mathrm{N}$-acetyl glucosamine). Hyaluronic acid is able to store extremely large water quantities, and on the skin it forms a moisturizing, viscoelastic, non sticky, air and light-permeable and thus invisible film. Hyaluronic acid optimized the water balance whereby the skin becomes smooth and more elastic (Brown and Jones, 2005). Also, it plays a key role to maintain the tissues integrity and to ease the cells migration in case of inflammation. Hyaluronic acid inhibits the pericellular migration of viruses and bacteria and sets on its structure the free radicals (antioxidant action), facilitating the healing process and the tissue regeneration (Zaleski et al., 2006; Favia et al., 2008).

The aim of this two month, prospective, randomized, double blind study was to evaluate the effect of vaginal hyaluronic acid in comparison with vaginal vitamin $\mathrm{E}$ on genital symptoms, vaginal $\mathrm{pH}$ and maturation of the vaginal epithelium using the maturation value (MV).

\section{MATERIALS AND METHODS}

This randomized controlled trial was conducted in number one health educational center of Ahvaz Jundishapur University, from
August to December, 2010. A preliminary power analysis was carried out to calculate the sample size for each group using a formula recommended by previous studies: $d=\Delta / S D$, where $\mathrm{d}$ is standardized difference, $\Delta$ is the smallest clinically significant difference and SD is standard deviation of the test group. The smallest clinically significant difference was considered as 10 , and the SD (15.96) was selected from the study performed by Ekin et al. (2011). Also, a standardized difference of 0.62 was obtained using nomogram. The power analysis suggested that a sample of 22 women in each group would provide a power of $80 \%$, at $5 \%$ significance.

\section{Preparing the drugs}

Hyaluronic acid and vitamin $E$ suppositories with weight of $1 \pm 0.04$ g containing Suppocire AM-15, a semi-synthetic fatty acid glyceride (courtesy of Gattefosse, Lyon, France) as the base for all suppositories and $1 \mathrm{mg}$ vitamin $\mathrm{E}$ or $5 \mathrm{mg}$ hyaluronic acid sodium salt were prepared by a pharmaceutical technician who was not included the clinical trial. The suppositories were held refrigerated until the time of their usage.

\section{Randomization}

Using a random numbers table for randomization, random numbers were assigned to each package. The patients and the medical investigator were not familiar with the content of each package.

\section{Participants}

During the 8-week study, the efficacy of $1 \mathrm{mg}$ vitamin $\mathrm{E}$ vaginal suppositories was compared with the vaginal suppositories containing $5 \mathrm{mg}$ hyaluronic acid sodium salt (HA). A total of 44 women were enrolled in the study. Inclusion criteria were, age between 45 and 65 years, with physiological menopause for at least 1 year or have hormone test with Follicle stimulating hormone (FSH) level more than 40 unit, presence of normal pap smears in the last 3 months, presenting symptom of vaginal atrophy, vaginal $\mathrm{pH}$ more than 5 , superficial vaginal cells with $5 \%$ or less and sexual activity. Exclusion criteria were; vaginal infection, genital abnormalities, the use of sex hormones within the 8 weeks preceding study, genital bleeding of unknown cause, use of phytoestrogens such as soy, red clover, fenugreek, and vitex within the last one month.

\section{Intervention}

The subjects were randomized into two groups: group I $(n=22)$ treated with vaginal suppositories containing $1 \mathrm{mg}$ vitamin $E$ daily for 14 days, and subsequently, one suppository three days a week and group II $(n=22)$ treated with vaginal suppositories in the form of HA, $5 \mathrm{mg}$ for the same period. The participants were also instructed to insert the suppositories at the same time each day. 4 patients discontinued the study: two in HA group (because of failure to follow-up) and two in vitamin $E$ group ( 1 because of lost at followup and 1 because of noncompliance) (Figure 1). Evaluations for efficacy of the treatment modalities occurred at eighth weeks.

\section{Outcome measures}

The symptoms of atrophic vaginitis evaluated in a composite vaginal score, including vaginal dryness, soreness, irritation, and 


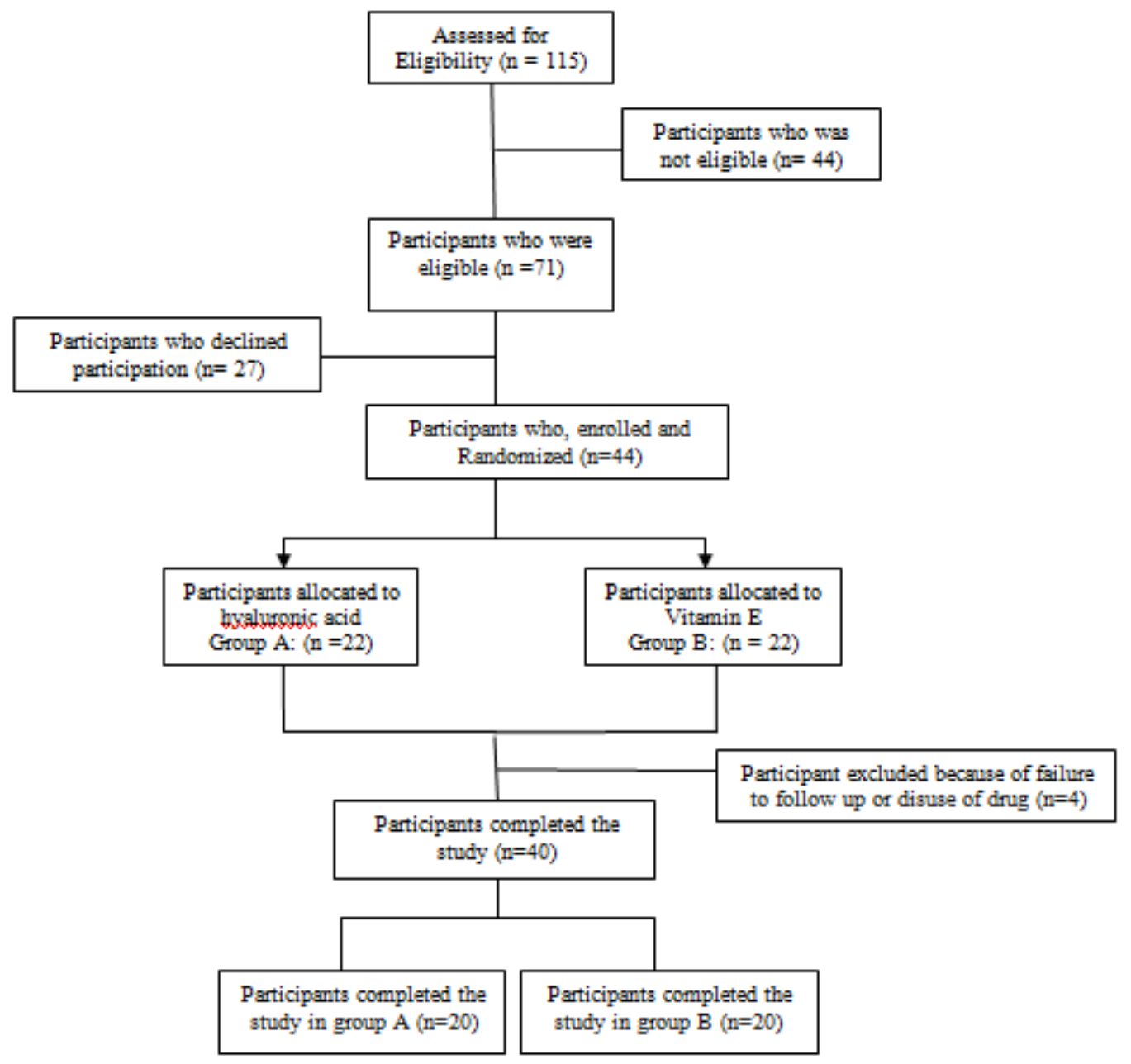

Figure 1. Recruitment and participation.

dyspareunia. Assessments of these vaginal symptoms were conducted at baseline (week 0 ) and week 8 . The severity of each symptom was self-assessed and received a grade based on a 4point scale $(0=$ none, $1=$ mild, $2=$ moderate, $3=$ severe $)$. $A$ composite score of these symptoms (mean of the individual symptom scores for dryness, soreness, irritation and dyspareunia) was then generated. Additional efficacy assessments included vaginal $\mathrm{pH}$ and vaginal cytology. Vaginal $\mathrm{pH}$ was measured by $\mathrm{a} \mathrm{pH}$ indicator strip inserted into the vagina in intervals in 4-point scale, respectively ( $\mathrm{pH}<5(0), 5$ to 5.49 (1), 5.5 to 6.49 (2), and more than 6.49 (Kaufman et al., 1989). Vaginal cytology specimens were collected at screening and the end of the treatment. Specimens were obtained by scraping the right and left lateral vaginal walls (midway between the fornix and introitus) with a wooden spatula. The cells and mucus that were collected were then mixed in a fixative to form a cell suspension. Vaginal cell samples were analyzed blindly by two experienced cytologists. The number of superficial, intermediate, and parabasal cells were counted and the percentage of each cell type calculated. These percentages were utilized in the following equation to determine the Maturation Index of the vaginal mucosa (Willhite and O'Connell, 2001). The vaginal maturation value (MV) was calculated according to the formula, MV $=[(0 \times$ Parabasal cells $(\%))+(0.5 \times$ Intermediate cells $(\%))+(1.0 \times$
Superficial cells (\%)].

\section{Statistical analysis}

For all efficacy variables, statistical analysis was carried out by SPSS version 16. Descriptive statistics were performed for each variable. Statistical analysis was performed using independent $t$ test and chi-square test to compare patients' baseline characteristics and the genital scores, $\mathrm{MV}$, and vaginal $\mathrm{pH}$ at basal condition and at the end of the study in the two groups. Paired t test was used for the comparison of the parameters in two groups. Data are expressed as mean $\pm S D$; the significance level was set up at $p$ less than 0.05 .

\section{Ethical considerations}

This trial was approved by the Research Ethics Committee of Ahvaz Jundishpur University of Medical sciences and registered within the Iranian registry of clinical trials (http://irct.ir). Women completed informed written consent form. Each woman was assigned an ID code, ensuring data set anonymity. Women could withdraw 
from the study at any point.

\section{RESULTS}

Mean age of the patients in HA group (54 \pm 5.16$)$ and vitamin $E$ group $(54.9 \pm 4.38)$ was not significantly different. The patients were menopausal for $5.55 \pm 4.77$ years in HA group and $6.1 \pm 5.25$ years in vitamin $E$ group, respectively $(P>0.05)$. At the baseline visit in $\mathrm{HA}$ group, burning was severe in $15 \%$ of women and absent in $35 \%$ of women; the symptom progressively disappeared during the treatment. Also in vitamin E group, burning was severe in $10 \%$ of women and absent in $60 \%$ of women; the symptom progressively reduced in intensity or disappeared and at the end of treatment only $10 \%$ of women complained of mild burning (Table I).

At the baseline visit in HA group, itching was severe in $5 \%$ of women and absent in $60 \%$ of women; the symptom progressively disappeared during the treatment. Also in vitamin $E$ group, itching was severe in $10 \%$ of women and absent in $55 \%$ of women; the symptom progressively reduced in intensity or disappeared and at the end of treatment, only $5 \%$ of women complained of mild itching. Also at the baseline visit in HA group, dyspareunia was severe in $20 \%$ of women and absent in $25 \%$; the symptom progressively reduced in intensity or disappeared and at the end of treatment only $5 \%$ of women complained of mild dyspareunia. Also in vitamin E group, dyspareunia was severe in $10 \%$ of women and absent in $20 \%$ of women; the symptom progressively reduced in intensity or disappeared and at the end of treatment only $5 \%$ of women complained of mild dyspareunia, and at the baseline visit in HA group, vaginal dryness was severe in $15 \%$ of women and absent in $10 \%$ of women; the symptom progressively reduced in intensity or disappeared and at the end of treatment only $10 \%$ of women complained of mild vaginal dryness. Also in vitamin $\mathrm{E}$ group, vaginal dryness was severe in $20 \%$ of women and absent in $10 \%$ of women; the symptom progressively reduced in intensity or disappeared and at the end of treatment only $45 \%$ of women complained of mild vaginal dryness (Table 1).

The mean composite score of vaginal symptoms in HA group was significantly different before and after the treatment and decreased from 4.70 at baseline to 0.15 at last visit $(P=0.001)$. Also in vitamin $E$ group, the mean composite score was significantly different before and after the treatment and decreased from 4.65 at baseline to 0.65 at last visit $(P=0.001)$. The composite score of vaginal symptoms was not significantly different at the beginning of the treatment in both groups mean $=4.70$, vitamin $\mathrm{E}$ (mean $=4.65, \mathrm{P}=0.48$ ). But a significant improvement in genital symptoms was observed at the end of the study in both groups. Treatment with HA resulted in significantly greater improvement in mean genital score $(\mathrm{HA}$ mean $=0.15)$ than treatment with vitamin $E$ (Vit $E$ mean $=0.65),(P=0.03)$ (Table 2).

The vaginal $\mathrm{pH}$ in $\mathrm{HA}$ group was significantly different before and after the treatment and decreased from 6.20 at baseline to 4.975 after treatment $(P=0.001)$. Also in vitamin $\mathrm{E}$ group, vaginal $\mathrm{pH}$ was significantly different before and after the treatment and decreased from 6.17 at baseline to 5.125 at last visit $(P=0.001)$. Therefore, vaginal $\mathrm{pH}$ was significantly decreased in both groups after treatment $(P=0.001)$, especially in the patients treated with $\mathrm{HA}$, without difference between the two groups (HA group $\mathrm{pH}=4.975$, Vit $\mathrm{E} \mathrm{pH}=5.125)(\mathrm{p}=$ 0.443 ) (Table 3). The vaginal maturation values in HA group was significantly different before and after the treatment and increased from 7.80 at baseline to 60.52 after treatment $(P=0.001)$. Also in vitamin $E$ group, vaginal maturation values was significantly different before and after the treatment and increased from 9.55 at baseline to 24.50 at last visit $(P=0.001)$. The vaginal maturation values (VMV) were also significantly improved in both study groups after 8 weeks of treatment $(P=$ 0.001 ), while the mean maturation value was significantly higher in HA group (60.52) when compared with vitamin $E$ group (24.50), respectively $(P=0.001)$ (Table 4).

\section{DISCUSSION}

Vaginal atrophy is a common problem after menopause and its severity increases with duration of missing period (Galhardo et al., 2006). Consequently, women with atrophic vagina may have problems including sexual dysfunction, pain, bleeding, and loss of vaginal elasticity. The degree of estrogen deficient vaginal atrophy can be evaluated subjectively from the patients' symptoms and/or vaginal examination, and objectively from vaginal $\mathrm{pH}$ testing and/or vaginal cytology (van der Laak et al., 2002; Gupta et al., 2006; Nilsson et al., 1995). Brizzolara in the United States found that a vaginal $\mathrm{pH}>4$ is associated with the increase in number of parabasal cells $(\geq 20 \%$ ) in smears from the proximal to mid vagina. According cytological definitions, in atrophic vaginitis, there is an increase in parabasal and intermediate cells in comparison with superficial cells that illustrates low estrogen effect (Immanuel et al., 2011). The first-line treatments include nonhormonal vaginal lubricants and moisturizers (Society, 2007). Water-based lubricants, vaginal moisturizers and vitamin $\mathrm{E}$ oil are some of the nonhormonal treatment options (Castelo-Branco et al., 2005).

In this study, we have studied the effect of hyaluronic acid in atrophic vaginitis. Because vagina also looses collagen and water retaining ability at menopause, hyaluronic acid is used as an adjuvant of repairing processes of the atrophic and dystrophic states of the vaginal mucosa, senile dryness also due to estrogen 
Table 1. The frequency of vaginal complaints before and after treatment in two groups.

\begin{tabular}{|c|c|c|c|c|c|c|c|c|c|}
\hline \multirow{3}{*}{ Group } & \multirow{3}{*}{$\begin{array}{l}\text { Severity of } \\
\text { symptoms }\end{array}$} & \multirow{2}{*}{\multicolumn{2}{|c|}{$\begin{array}{c}\text { Dryness } \\
\text { Treatment } \mathbf{n}(\%) \\
\end{array}$}} & \multirow{2}{*}{\multicolumn{2}{|c|}{$\begin{array}{c}\text { Burning } \\
\text { Treatment } \mathbf{n}(\%) \\
\end{array}$}} & \multirow{2}{*}{\multicolumn{2}{|c|}{$\begin{array}{c}\text { Itching } \\
\text { Treatment } \mathbf{n}(\%)\end{array}$}} & \multirow{2}{*}{\multicolumn{2}{|c|}{$\begin{array}{c}\text { Dyspareunia } \\
\text { Treatment } \mathbf{n}(\%) \\
\end{array}$}} \\
\hline & & & & & & & & & \\
\hline & & After & Before & After & Before & After & Before & After & Before \\
\hline \multirow{4}{*}{ Vit E } & None & $11(55)$ & $2(10)$ & $18(90)$ & $12(60)$ & 19(95) & $11(55)$ & 19(95) & $4(20)$ \\
\hline & Mild & $9(45)$ & $6(30)$ & $2(10)$ & $4(20)$ & 1(5) & $3(15)$ & $1(5)$ & $7(35)$ \\
\hline & Moderate & $0(0)$ & $8(40)$ & $0(0)$ & $2(10)$ & $0(0)$ & $4(20)$ & $0(0)$ & $7(35)$ \\
\hline & Severe & $0(0)$ & $4(20)$ & $0(0)$ & $2(10)$ & $0(0)$ & $2(10)$ & $0(0)$ & $2(10)$ \\
\hline \multirow{4}{*}{$\mathrm{HA}$} & None & $18(90)$ & $2(10)$ & $20(100)$ & $7(35)$ & $20(100)$ & $12(60)$ & 19(95) & $5(25)$ \\
\hline & Mild & $2(10)$ & $6(30)$ & $0(0)$ & $7(35)$ & $0(0)$ & $5(25)$ & 1(5) & $7(35)$ \\
\hline & Moderate & $0(0)$ & $9(45)$ & $0(0)$ & $3(15)$ & $0(0)$ & $2(10)$ & $0(0)$ & $4(20)$ \\
\hline & Severe & $0(0)$ & $3(15)$ & $0(0)$ & $3(15)$ & $0(0)$ & $1(5)$ & $0(0)$ & $4(20)$ \\
\hline
\end{tabular}

Table 2. The comparison of composite score of vaginal symptoms (CSVS) before and after treatment in two groups.

\begin{tabular}{lccc}
\hline \multirow{2}{*}{ Parameters } & Vit E Group & HA Group & \multirow{2}{*}{ P Value } \\
\cline { 2 - 3 } & Mean \pm SD & Mean \pm SD & \\
\hline CSVS before treatment & $2.41 \pm 4.650$ & $4.70 \pm 2.81$ & 0.48 \\
CSVS after treatment & $0.650 \pm 0.875$ & $0.150 \pm 0.489$ & 0.032 \\
P Value & 0.001 & 0.001 & \\
\hline
\end{tabular}

Table 3. The comparison of vaginal $\mathrm{pH}$ before and after treatment in two groups.

\begin{tabular}{lccc}
\hline \multirow{2}{*}{ Parameters } & Vit E Group & HA Group & \multirow{2}{*}{ P Value } \\
\cline { 2 - 3 } & Mean \pm SD & Mean \pm SD & \\
\hline Vaginal pH (before treatment) & $6.17(0.862)$ & $6.20(0.695)$ & 0.404 \\
Vaginal pH (after treatment) & $5.125(0.666)$ & $4.975(0.572)$ & 0.443 \\
P Value & 0.001 & 0.001 & \\
\hline
\end{tabular}

Table 4. The comparison of vaginal maturation value before and after treatment in two groups.

\begin{tabular}{lccc}
\hline \multirow{2}{*}{ Parameters } & Vit E Group & HA Group & \multirow{2}{*}{ P Value } \\
\cline { 2 - 3 } & (mean \pm SD) & (mean \pm SD) & \\
\hline Vaginal maturation value (before treatment) & $9.55(6.36)$ & $7.80(7.48)$ & 0.431 \\
Vaginal maturation value (after treatment) & $24.50(8.78)$ & $60.52(8.67)$ & 0.001 \\
P Value & 0.001 & 0.001 & \\
\hline
\end{tabular}

deficiency. Tea et al., (2006) studied the efficacy and safety of hyaluronic acid vaginal tablets in 95 patients suffering from hormone or chemotherapy-induced atrophic vaginitis due to breast cancer. They have found a significant reduction (70\%) in symptoms of atrophic vaginitis. Costantino et al., (2008) performed a clinical trial to investigate the effects of vaginal suppositories containing hyaluronic acid, vitamins $\mathrm{A}$ and $\mathrm{E}$, with the aim of testing its safety and efficacy in post-menopausal women with urogenital atrophy.

One hundred and fifty post-menopausal women were treated with daily application of one vaginal suppository for 14 days continuously. Then, for other 14 days, the administration of one suppository per day, one day in one 
day out. The results showed a marked effect of the tested product on the vaginal dryness and on all other symptoms and signs with statistically significant reductions since the first week of treatment (Gupta et al., 2006). We have also found comparable results with those two trials. In our study, we have found significant improvement in vaginal symptoms, vaginal $\mathrm{pH}$ and vaginal maturation index. This improvement was more significant in the patients who take vaginal suppositories containing hyaluronic acid. The results of this investigation should be considered preliminary and need to be verified in larger, prospective studies.

\section{ACKNOWLEDGMENTS}

The study was supported by a grant from vice chancellor of research, Ahvaz Jundishapur University of Medical Sciences. We are indebted to those who commented on early drafts of this article, in particular we wish to thank Mr. M. H. Haghighizadeh, MS.c in statistics, Department of Statistics and Mathematics, for his helpful comments and statistical analysis.

\section{REFERENCES}

Barlow DH, Cardozo LD, Francis RM, Griffin M, Hart DM, Stephens E, Sturdee DW (1997). Urogenital ageing and its effect on sexual health in older British women. BJOG: An. Int. J. Obstet. Gynaecol. 104(1):87-91.

Brown M, Jones S (2005). Hyaluronic acid: a unique topical vehicle for the localized delivery of drugs to the skin. J. Eur. Acad. Dermatol. Venereol. 19(3):308-318.

Castelo-Branco C, Cancelo MJ, Villero J, Nohales F, Juliá MD (2005). Management of post-menopausal vaginal atrophy and atrophic vaginitis. Maturitas 52:46-52.

Costantino D, Guaraldi C, Minozzi F, Chipaila N, Unfer V, Minozzi M, Franceschini G, Magno S, Fabbri C, Chiesa F (2008). Effectiveness and safety of vaginal suppositories for the treatment of the vaginal atrophy in postmenopausal women: an open, non-controlled clinical trial. Eur. Rev. Med. Pharmacol. Sci. 12(6):411-416.

Ekin M, Yaşar L, Savan K, Temur M, Uhri M, Gencer I, Kıvanç E (2011). The comparison of hyaluronic acid vaginal tablets with estradiol vaginal tablets in the treatment of atrophic vaginitis: a randomized controlled trial. Arch. Gynecol. Obstet. 283(3):539-543.

Favia G, Mariggio M, Maiorano F, Cassano A, Capodiferro S, Ribatti D (2008). Accelerated wound healing of oral soft tissues and angiogenic effect induced by a pool of aminoacids combined to sodium hyaluronate (AMINOGAM). J. Biol. Regul. Homeost. Agents 22(2):109.

Galhardo C, Soares Jr. J, Simoes R, Haidar M, Rodrigues LG, Baracat $E$ (2006). Estrogen effects on the vaginal $\mathrm{pH}$, flora and cytology in late postmenopause after a long period without hormone therapy. Clin. Exp Obstet. Gynecol. 33(2):85.
Gupta S, Kumar N, Singhal N, Manektala U, Jain S, Sodhani P (2006). Cytohormonal and morphological alterations in cervicovaginal smears of postmenopausal women on hormone replacement therapy. Diagn. Cytopathol. 34(10):676-681.

Immanuel AI, Wantania J, Suparman E, Lintong P (2011). Clinical appearance and vaginal cytology of atrophic vaginitis in postmenopausal women. Indones. J. Obstet. Gynecol. 34(2):92-96.

Johnston S, Farrell S, Bouchard C, Beckerson L, Comeau M, Lefebvre G, Papaioannou A (2004). The detection and management of vaginal atrophy. J. Obstet. Gynaecol. Can. 26(5):503.

Kaufman R, Friedrich E, Gardner H (1989). Atrophic, desquamative, and postradiation vulvovaginitis. Benign diseases of the vulva and vagina: pp.419-424.

Mehta A, Bachmann G (2008). Vulvovaginal complaints. Clin. Obstet. Gynecol. 5(3):549.

Neggers YH, Nansel TR, Andrews WW, Schwebke JR, Yu K, Goldenberg RL, Klebanoff MA (2007). Dietary intake of selected nutrients affects bacterial vaginosis in women. J. Nutr. 137(9):21282133.

Nilsson K, Risberg B, Heimer G (1995). The vaginal epithelium in the postmenopause-cytology, histology and $\mathrm{pH}$ as methods of assessment. Maturitas 21(1):51-56.

Pandit L, Ouslander JG (1997). Postmenopausal vaginal atrophy and atrophic vaginitis. Am. J. Med. Sci. 314(4):228.

Society NAM (2007). The role of local vaginal estrogen for treatment of vaginal atrophy in postmenopausal women: 2007 position statement of The North American Menopause Society. Menopause 14:355-369.

Sturdee D, Panay N (2010). Recommendations for the management of postmenopausal vaginal atrophy. Climacteric 13(6):509-522.

Tea M, Priemer V, Kubista E (2006). News: Efficacy and safety of hyaluronic acid suppositories (Cikatridina $(\mathrm{R})$ ) in the treatment of hormone-or chemotherapy-induced vaginal atrophy in breast cancer patients. J. Reprod. Fertil. 16:17-19.

vander Laak J, de Bie L, De Leeuw H, de Wilde P, Hanselaar A (2002). The effect of Replens ${ }^{\circledR}$ on vaginal cytology in the treatment of postmenopausal atrophy: cytomorphology versus computerised cytometry. J. Clin. Pathol. 55(6):446-451.

Weisberg E, Ayton R, Darling G, Farrell E, Murkies A, O'Neill $S$, Kirkegard Y, Fraser IS (2005). Endometrial and vaginal effects of lowdose estradiol delivered by vaginal ring or vaginal tablet. Climacteric 8(1):83-93.

Willhite LA, O'Connell MB (2001). Urogenital atrophy: prevention and treatment. Pharmacother. J. Hum. Pharmacol. Drug Ther. 21(4):464480.

Zaleski KJ, Kolodka T, Cywes-Bentley C, McLoughlin RM, Delaney ML, Charlton BT, Johnson W, Tzianabos AO (2006). Hyaluronic acid binding peptides prevent experimental staphylococcal wound infection. Antimicrob. Agents Chemother. 50(11):3856-3860. 